\title{
Does India Increasing Potential Inclusive Growth Polices? A Critical Analysis
}

\author{
Dr.Nageswara Rao Dara \\ Post-Doctoral Fellow (UGC), Department of Economics, Andhra University, Visakhapatnam.
}

\begin{abstract}
World Economic Forum (WEF) 2016 reported that India has mostly been ranked in the bottom half of the 38 countries that make up our lower middle-income bracket. Particularly disappointing is its position in terms of Fiscal Transfers, where it ranks 37th out of 38. It also ranks very low at 32nd for Tax Code and 36th for social protection. The literature reviews show that India failed to understand the links between unemployment and labor market institutions that foster inclusive growth. India was missing major opportunities to reduce income inequality, access to health, education and failed to create economic infrastructure. The researcher will measure the potential of Indian inclusive growth policies towards the achievements of Sustainable Development Goals in India. In this context, the researcher will measure the idea of social opportunity function that is similar to social welfare function. The proposed methodologies are applied to the India using its micro unit-record household survey. The research results showed access to opportunities and basic infrastructure facilities were not reaching to needy poor people in India. Monitoring by means of the opportunity curve is the one-to-one relationship with the social opportunity function indicates inequalities are increasing day by day in the reform period.
\end{abstract}

Key Words: Inclusive Growth, Policies, Social Opportunity Function, Household Survey, Employment Opportunity.

\section{INTRODUCTION}

The word 'inclusive' has become not only fashionable but also quite relevant in our country. The Oxford Dictionary gives four meanings to the word, and the most inclusive meaning is "not excluding any section of society.' The Eleventh Five Year Plan "Towards faster and more inclusive growth" reflects the need to make growth 'more inclusive' in terms of benefits flowing through more employment and income to those sections of society which have been by-passed by higher rates of economic growth witnessed in recent years. The recognition of the need for more inclusive growth by our planners is a welcome shift in emphasis from mere increase in growth rates to improvement in standards of living of those below the poverty line through increase in employment opportunities as well as better delivery systems to ensure access to intended benefits by intended beneficiaries (Singh, 2012). Since last 25 years, India embarked on big-bang economic reforms in 1991. India had made towards faster and more inclusive growth policies after economic reforms. But, when we measure the inclusive growth outcomes, we may raise questions like what are the achievements in terms of growth and inclusive growth in the post-reform period? What are the issues in poverty measurement? Has poverty declined faster in the post-reform period? What are the determinants and policies needed for the reduction in poverty? Has inequality increased in the reform period? What should be done to reduce inequalities? This paper addresses these questions relating to economic reforms, poverty, and inequality.

\section{Defining Inclusive Growth}

Very recently, the report of the Eminent Persons Group that was initiated by ADB (2007) made reference to the term "inclusive growth", which emphasizes ensuring that the economic opportunities created by growth are available to all particularly the poor to the maximum possible extent. The growth process creates new economic opportunities that are unevenly distributed. The poor are generally constrained by circumstances or market failures that disable them to avail of these opportunities. As a result, the poor generally benefit less from growth than the non-poor. Thus, growth will generally be not pro-poor if left completely to markets. The government, however, can formulate policies and programs that facilitate the full participation in the new economic opportunities of those less well off. We may thus define inclusive growth as growth that not only creates new economic opportunities, but also one that ensures equal access to the opportunities(Ali, 2007) Inclusiveness of economic growth is a multidimensional concept. Yet, while the term "inclusive growth" has been widely used by Governments, international organizations and other stakeholders in recent years, there is still a lack of consensus on its concept and dimensions. Keeping in view the broad social objective of human well-being, inclusiveness as defined below encompasses the dimensions of economic inclusiveness, social 
inclusiveness, and environmental inclusiveness. To enhance inclusiveness there is need to focus on and analyse people's wellbeing the ultimate objective of any society by focusing on: (a) increasing the average standard of living of the population (captured by average real income per capita); (b) reducing income inequality; (c) reducing levels of extreme poverty; and (d) expanding and broadening equality in opportunities, such as access to public goods(Ali. J, 2007)

\section{Key Elements in Inclusive Growth}

In inclusive growth, there are three key measures that play a critical role in achieving the outcomes of inclusive growth: (i) creating employment opportunities and promoting higher productivity, (ii) developing human capabilities through adequate investment in basic social services of education and health, and (iii) providing social safety nets and targeted interventions to help those who are vulnerable and/or suffer from extreme deprivation. These three measures will be discussed in turn. The ultimate outcomes of inclusive growth are (i) sustainable and equitable growth, (ii) social inclusion, (iii) empowerment, and (iv) security. Economic growth is indeed an essential requirement for inclusive growth. For growth to be rapid and sustained, it should be broad-based across sectors and regions, and inclusive of the large part of the labor force, including the poor and vulnerable groups of the population. Social inclusion is the removal of institutional barriers and the enhancement of incentives to increase the access of all segments of the society to development opportunities. Empowerment is the enhancement of the assets and capabilities of diverse individuals and groups to function in and to participate in the growth process. Security encompasses improved management of the social risks arising out of development interventions. The objective of this paper is to provide an approach to defining and measuring inclusive growth. The study proposes a new methodology to capture inclusive growth, based on a social opportunity function similar to the idea of a social welfare function. The paper will be discussing in the following manner that to defining inclusive growth, failure of Indian inclusive growth policies reviews in a detailed analysis. The researcher will set out the analytical framework describing the methodology, will provide the empirical results with discussion and conclusion.

\section{Inclusive growth in Asia and the Pacific}

Global economic activity is picking up with a long-awaited cyclical recovery in investment, manufacturing, and trade.The International Monetary Fund (IMF) has warned that both India and China face the social risk of growing inequality. By implication, it is suggesting that there is a problem with the redistribution of incomes in both these economies as high economic growth rates are not reducing inequality. In its regional economic outlook for Asia and Pacific, IMF said that Asian countries are unable to replicate the "growth with equity" miracle and pointed out that inequality has only increased in the past two and a half decades, lowering the effectiveness of growth to combat poverty and preventing the building of a substantial middle class(IMF, 2016). IMF survey emphasized that the regional economic outlook for Asia and Pacific countries are unable to replicate the "growth with equity" miracle and pointed out that inequality has only increased in the past two and a half decades, lowering the effectiveness of growth to combat poverty and preventing the building of a substantial middle class. India's Gini coefficient rose to 51 by 2013, from 45 in 1990, mainly on account of rising inequality between urban and rural areas as well as within urban areas. China's Gini coefficient also rose to 53 in 2013, from 33 in 1990. At a time when inequality has been coming down for most of the world, the average net Gini coefficient for Asia rose to 40 in 2013 from 36 in 1990, the highest among the rest of the world.Gini coefficient is a widely used measure of inequality and takes into account income distribution among residents of a country(IMF, 2016). The income, in this case, has been calculated net of taxes and transfers. The higher the Gini coefficient, the greater is the inequality. The below figure below shows that: 
Figure: 1 Income Inequality in Global

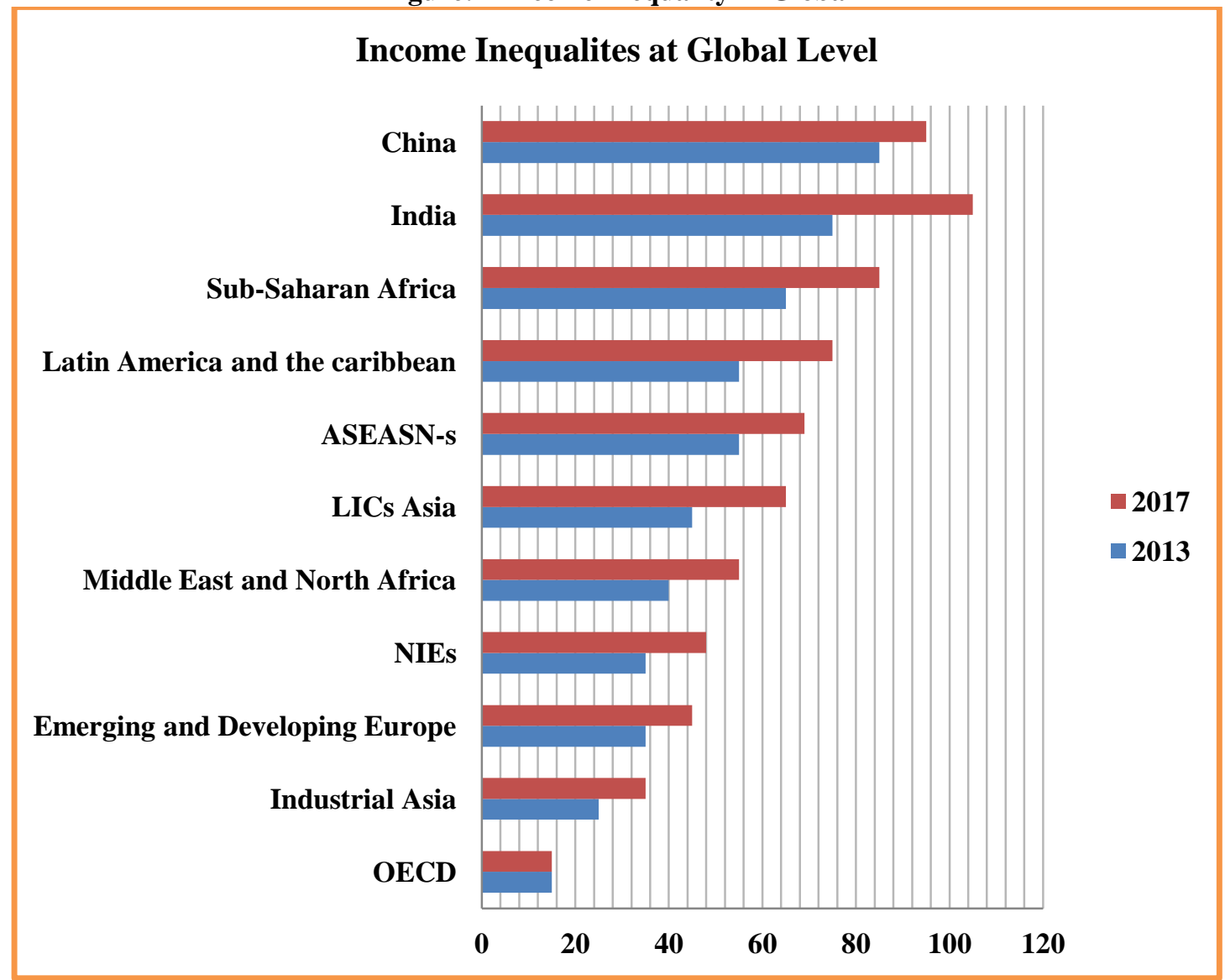

ASEAN-5: Indonesia, Malaysia, the Philippines, Singapore and Thailand

LIC: Low-Income Countries

NIEs: New Inustrailized Economies

OECD: Organisation for Economic Co-opration and Development

Source: IMF, 2017

The IMF report 2017 emphasized that clouded with significant uncertainty, and risks, on balance, remain slanted to the downside. Medium-term growth faces secular headwinds, including from population aging and sluggish productivity. Macroeconomic policies should continue to support growth while boosting resilience, external rebalancing, and inclusiveness. The region needs structural reforms to address its demographic challenges and to boost productivity. The recent growth momentum in the largest economies in the region remains particularly strong, reflecting policy stimulus in China and Japan, which in turn is benefiting other economies in Asia. More broadly across the region, forward-looking indicators such as the Purchasing Managers' Index suggest continued strength in activity into early 2017. According to IMF survey indicates that within-country income inequality has risen in most of Asia, in contrast to many regions. In some larger countries (such as China and India), spatial disparities, in particular between rural and urban areas, explain much of the increase," the report said. Figure 2 shows inequality in Asia. The IMF reports revisit the increasingly important topic of widening income inequality, focusing on Asia, home to more than half of the world's population. It contributes to a growing literature, including at the IMF, on the evolution and drivers of income inequality. 
Figure: 2 Income Inequalities in Asia

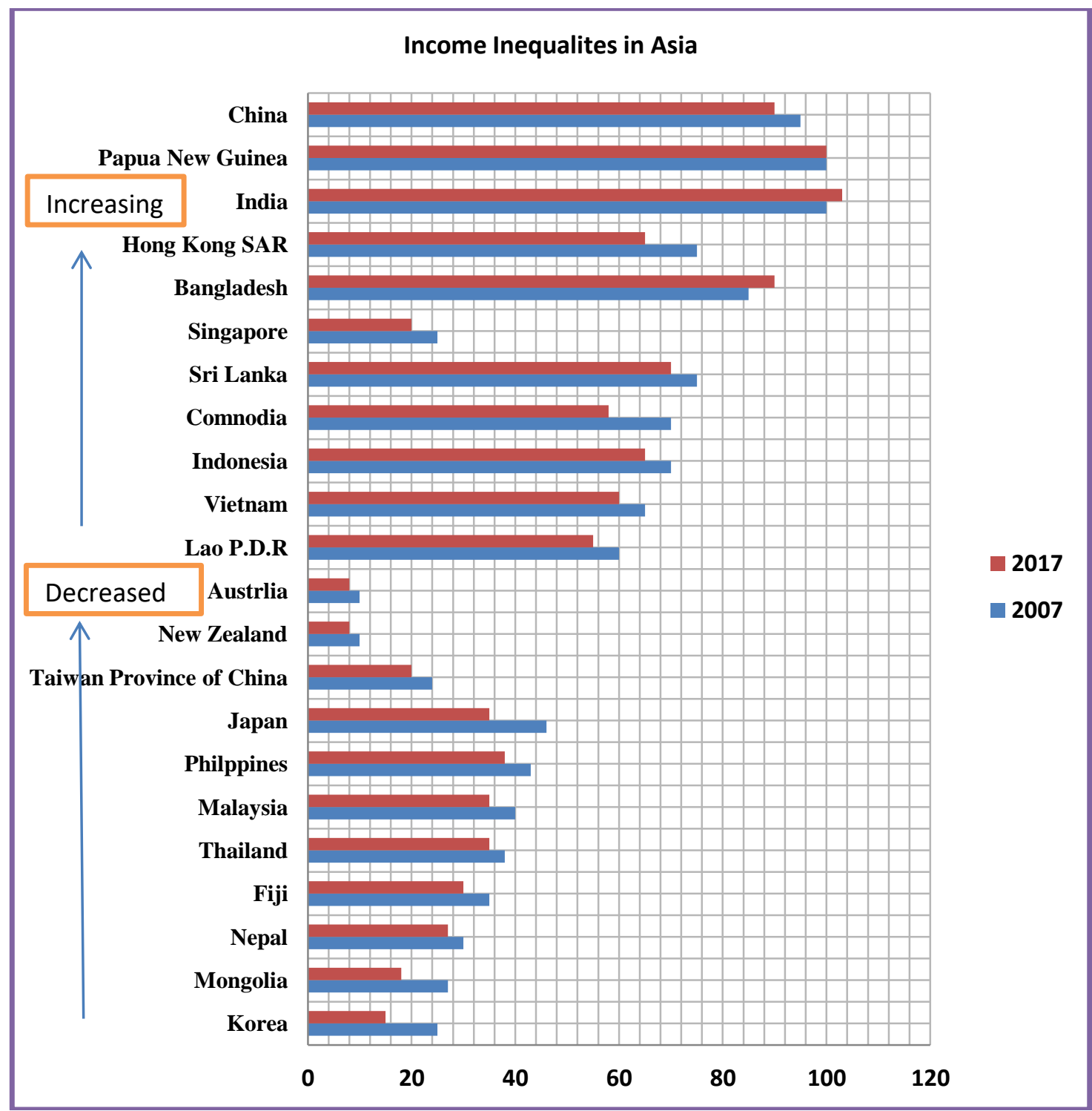

\section{Source: IMF Report, 2017}

\section{Inclusive growth in India}

India's government has made "inclusive growth" a key element of their policy platform, stating as a goal: "Achieving a growth process in which people in different walks of life... feel that they too benefit significantly from the process."(Ahluwalia, M, 2007). How a country may achieve a self-sustaining transition from traditional to industrial economies has been addressed by many contributions to development theory. Economic growth models do not establish or suggest, however, an explicit causal-effect relationship between a country's rates of economic growth and the resulting poverty reduction, although policymakers often assume an implicit connection. The current literature provides some guidelines about conditions under which economic growth might be 'inclusive' or 'pro-poor', although how these concepts should be defined remains controversial. One view is that growth is 'pro-poor' only if the incomes of poor people grow faster than those of the population as a whole, i.e., inequality declines (Kakwani, 2000). An alternative position is that growth should be considered to be pro-poor as long as poor people also benefit in absolute terms,

\section{Current Situation of Indian Inclusive Growth}

India has been ranked 60th among 79 developing economies, below neighboring China and Pakistan, in the inclusive development index, according to a WEF report. WEF's 'Inclusive Growth and Development Report 2017' said that most countries are missing important opportunities to raise economic growth and reduce 
inequality at the same time because the growth model and measurement tools that have guided policymakers for decades require significant readjustment.

While India is placed at the 60th spot, many of the neighboring nations are ahead in the rankings. China is ranked at the 15th position, Nepal (27th), Bangladesh (36th) and Pakistan (52nd). Two BRIC nations, Russia and Brazil, are at 13th and 30th places, respectively. Others in the top ten are Poland (4th), Romania (5th), Uruguay (6th), Latvia (7th), Panama (8th), Costa Rica (9th) and Chile (10th). "India, with a score of only 3.38, ranks 60th among the 79 developing economies on the IDI, despite the fact that its growth in GDP per capita is among the top 10 and labor productivity growth has been strong. See the figure below as follows

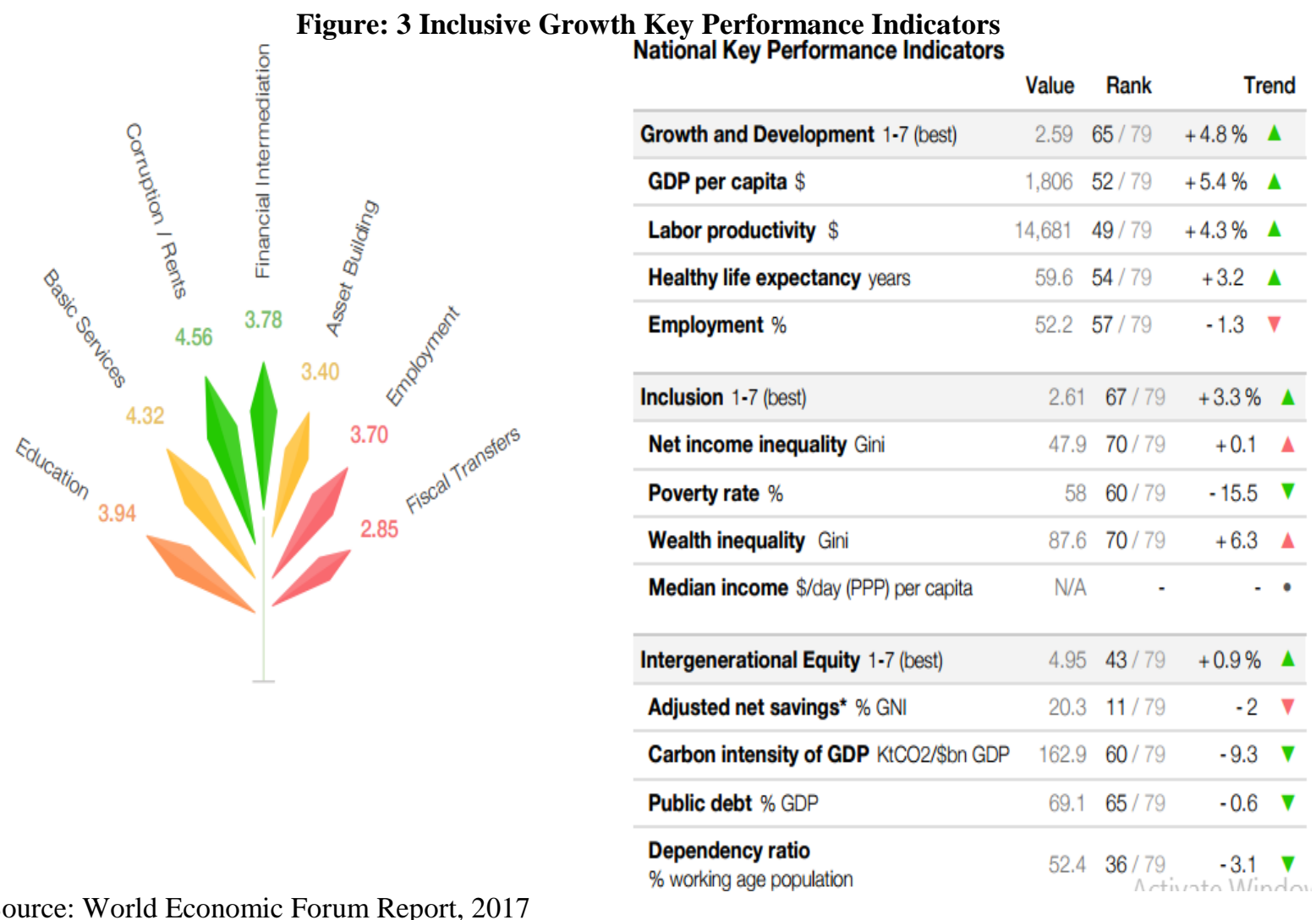

India mostly ranked in the bottom half of the 38 countries that comprised the report's 'lower middleincome bracket', which included Egypt, Ghana, Ukraine, Iran, and Nigeria, among others. This category identifies countries that have enough income to lift much of the population above subsistence level but are still struggling to do so.India ranked 37th out of 38 countries in fiscal transfers, 36th in social protection and 38th (at the bottom) in small business ownership. The World Economic Forum noted that one of the reasons for its poor performance is that India under-exploits the use of fiscal transfers. "It's income tax is regressive and social spending remains low, which limits the accessibility of health care and other basic services. Sanitation continues to be a problem across the board," the report says (Richard Samans, Jennifer Blanke, Gemma Corrigan, Margareta Drzeniek, 2015). This is the first time that the WEF has undertaken such a study, which it conducted over the last two years. Other categories that countries fall into (apart from the 'lower middle-income bracket') are 'advanced', 'upper-middle income' and 'lower-income'. Through this exercise, WEF aims to understand how countries can make use of policy incentives and institutional mechanisms so that all its citizens can enjoy the benefits of economic growth without dampening incentives to work, save and invest.

Table: 1 National Key Performance Indicators of Inclusive Growth

\begin{tabular}{|l|r|r|r|r|}
\hline Key performance Indicators & Value & Rank & \multicolumn{3}{|c|}{ Trend } \\
\hline Growth and Development1-7 (best) & 2.59 & $65 / 79$ & $+4.8 \%$ & ム \\
\hline GDP per capita\$ & 1,806 & $52 / 79$ & $+5.4 \%$ & $\boldsymbol{\Lambda}$ \\
\hline Labor productivity \$ & 14,681 & $49 / 79$ & $+4.3 \%$ & $\boldsymbol{\Delta}$ \\
\hline
\end{tabular}


Does India Increasing Potential Inclusive Growth Polices? A Critical Analysis

\begin{tabular}{|c|c|c|c|c|}
\hline Key performance Indicators & Value & Rank & \multicolumn{2}{|c|}{ Trend } \\
\hline Healthy life expectancyyears & 59.6 & $54 / 79$ & +3.2 & $\Delta$ \\
\hline \multirow[t]{2}{*}{ Employment\% } & 52.2 & $57 / 79$ & -1.3 & $\boldsymbol{\nabla}$ \\
\hline & Value & Rank & \multicolumn{2}{|c|}{ Trend } \\
\hline Inclusion1-7 (best) & 2.61 & $67 / 79$ & $+3.3 \%$ & $\boldsymbol{\Delta}$ \\
\hline Net income inequalityGini & 47.9 & $70 / 79$ & +0.1 & $\boldsymbol{\Delta}$ \\
\hline Poverty rate $\%$ & 58 & $60 / 79$ & -15.5 & $\boldsymbol{\nabla}$ \\
\hline Wealth inequality Gini & 87.6 & $70 / 79$ & +6.3 & $\boldsymbol{\Delta}$ \\
\hline \multirow[t]{2}{*}{ Median income\$/day (PPP) per capita } & N/A & - & - & - \\
\hline & Value & Rank & \multicolumn{2}{|c|}{ Trend } \\
\hline Intergenerational Equity1-7 (best) & 4.95 & $43 / 79$ & $+0.9 \%$ & $\mathbf{\Delta}$ \\
\hline Adjusted net savings*\% GNI & 20.3 & $11 / 79$ & -2 & $\nabla$ \\
\hline $\begin{array}{l}\text { Carbon intensity of GDPKtCO } 2 / \$ \text { bn } \\
\text { GDP }\end{array}$ & 162.9 & $60 / 79$ & -9.3 & $\boldsymbol{\nabla}$ \\
\hline Public debt $\%$ GDP & 69.1 & $65 / 79$ & -0.6 & $\boldsymbol{\nabla}$ \\
\hline $\begin{array}{l}\text { Dependency ratio } \% \text { working age } \\
\text { population }\end{array}$ & 52.4 & $36 / 79$ & -3.1 & $\nabla$ \\
\hline
\end{tabular}

Sources: World Economic Forum Report, 2017

\section{Growth and inequality}

While many Indians live on less than a dollar a day, the country boasts a relatively high number of millionaires. The recent literature review indicates that there is increasing huge gap between rich and the poor, what is the factors behind this gap? India is home to the fourth largest number of millionaires in Asia, with the country hosting 236,000 individuals with assets of over $\$ 1$ million by the end of 2015 , according to a recent report published by South Africa-based New World Wealth. The South Asian nation also boasts more multimillionaires than any other country in the region after China and Japan - a reflection of the enormous wealth created in India over the past two decades following the liberalization of its economy. At the same time, this trend seems to have widened the gap between those at the top and the bottom of the wealth distribution, despite India's impressive economic growth rates. The Gini coefficient is the standard measure of inequality, with zero representing total equality, and 100 indicating complete inequality. In India, the index rose from 30.8 in 1993 to 33.9 in 2009, the year for which latest World Bank data is available (DW Report, 2016).

\section{Rural and Urban Income Inequalities top 20 States in India}

The scenario of India where the rural-urban income gap has increased a part of which is contributed by the higher levels of inflation in the rural sector. Similarly, the large differences in human capital accumulation across states have also contributed to the growing disparities in per capita income in the states and increased inequalities.Strangely growing inequality levels in India is also on account of differences in educational attainments in the last two decades. However, in the rural areas, this is caused by the growing inequality in years of education of the head of households in the urban areas it is caused by the higher returns into education in high skilled service sectors and occupations. Other factors causing inequalities include fiscal constraints. In both countries tax revenues remain low as a percentage of the GDP and service delivery in important sectors like health and education remain clogged. Pro-poor growth in India has also been hampered by the labor market rigidities which has pushed most of the employment to the unorganized sector. Overall the study concludes by pointing out that though high growth in Asia has made a substantial dent on poverty higher income inequalities have lowered the effectiveness of growth and prevented the growth of a large middle class. So reversing the rising trends in inequality would hence require the government to address the growing inequality in opportunities by improving access to better health services, higher education and better targeting of social benefits (Pyaralal Raghavan, 2016). 


\section{Failures of Indian Inclusive Growth Policies and Outcomes}

There are There are failures in policies, processes, and outcomes in the post-reform period. The post-reform period policies particularly, inclusive growth policies are indicating that failures, which are elaborated below. These are mainly as follows:

\section{(a) Slow Infrastructure development}

Although there is a lot of progress, almost all indicators score poorly if one looks at India's infrastructure particularly compared with countries like China. For example, power shortage is perennial in India. This is one of the single biggest constraints for our growth. Meeting the energy requirements for growth of this magnitude in a sustainable manner presents a major challenge. It is not surprising that the index of infrastructure across states is highly correlated with per capita income and level of poverty. In the post-reform period, we have a much greater dependence on private investment through different forms of public-private partnerships (PPPs) than was the case when the reforms started. PPPs have not met the expectations. (Ahluwalia, 2012) says "policy is being framed such that PPPs should be a means of bringing private money into public projects and not siphoning public money into private projects!". Maybe a different approach is needed on PPPs. Moreover, clearances on the environment and land acquisition should be faster so that investments can be improved. Similarly, ease of doing business in India has to be undertaken. Vijay Kelkar committee's recommendations would be useful to revive PPP in infrastructure projects. Particularly energy security is important for economic growth and providing power to many households $(\mathrm{S}, 2016)$.

\section{(b) Failure in increasing labour intensive manufacturing}

The rise in manufacturing employment is need of the hour. The share of manufacturing in total employment has been almost stagnant at 11 to 12 percent for a long time. It increased marginally to 13 per cent in 2011-12. In 2010, India accounts for 1.4\% of the world exports of manufactures while the share of China is a whopping 15\%. The reforms since 1991 have not been comprehensive enough to remove the bias towards capital and skill-intensive industries. Also, there are distortions in input markets like land and labor. For example, some strongly believe that among other things, labor market reforms are one of the key factors for the revival of manufacturing sector particularly in the organized sector(S, 2016).

A study by Ramaswamy and Agarwal (2013) strongly suggest that services sector would be an unlikely destination for the millions of low-skilled job seekers. India needs to focus on manufacturing sector to provide large scale employment. Manufacturing has the capability because it has stronger backward linkages, unlike the services sector. We cannot afford to neglect to manufacture at this stage of development. The policy signals have to clearly say that we stand to support manufacturing activity in a big way. India needs to focus on manufacturing sector to provide large scale employment. Manufacturing has the capability because it has stronger backward linkages. We cannot afford to neglect to manufacture at this stage of development. Labor intensity of organizing manufacturing sector has to be improved apart from increasing the productive employment in SMEs and unorganized manufacturing(Ramaswamy, 2013).

\section{(c) Not taking advantage of demographic dividend.}

It is known that with the demographic dividend, there will be large numbers joining the labor force. Labour force in India is expected to increase by 32 per cent while it will decline by nearly 5.0 percent in China over the next 20 years. India is supposed to have the surplus of 56 million while rest of the world will have a shortage of 47 million working population. Demographic dividend varies across regions. Northern states will have young population (dependency ratio in Bihar 1.05, UP 1.08)Southern states have already started aging (dependency ratio TN 1.74, Kerala 1.79). There has been sluggish progress in education and skill levels of workers. The young population is an asset only if it is educated, skilled and finds productive employment. During the Twelfth Five-Year Plan (2012-17), 50 million non-farm employment opportunities are proposed to be created and at least the equivalent number of people would be provided skill certification. There are huge challenges in raising education and skills of workers and population (Kannan, 2014).

In India, education and skills of workers are low although it has been rising over time. As shown in Table 2 even in 2011-12, around 78 per cent of rural female, 56 percent of rural males, 47 percent of urban females and 30 percent of urban males are either illiterate or have been educated up to primary level. Only about 5 percent of rural females and 13 per cent of rural males have education higher secondary and above. In the case of urban workers, the share of graduates and above rose significantly, particularly for urban females. 
Does India Increasing Potential Inclusive Growth Polices? A Critical Analysis

Table:2 Education of Workers: 1999-00 to 2011-12 (Usual Principal and Subsidiary Status, UPSS)

\begin{tabular}{|c|c|c|c|c|c|c|}
\hline \multirow[t]{3}{*}{ Particulars } & Female & & & Male & & \\
\hline & $\begin{array}{l}2000- \\
04\end{array}$ & $\begin{array}{l}2004- \\
05\end{array}$ & $\begin{array}{l}2012- \\
14\end{array}$ & $\begin{array}{l}2000- \\
04\end{array}$ & $\begin{array}{l}2004- \\
05\end{array}$ & $\begin{array}{l}2012- \\
14\end{array}$ \\
\hline & & & \multicolumn{2}{|c|}{ Rural } & & \\
\hline Not literate & 73.9 & 66.4 & 56.3 & 39.6 & 33.8 & 28.0 \\
\hline $\begin{array}{l}\text { Literate\&up to } \\
\text { primary }\end{array}$ & 15.5 & 18.4 & 21.8 & 27.3 & 29.4 & 27.6 \\
\hline Middle & 6.2 & 8.7 & 10.8 & 16.3 & 18.1 & 19.0 \\
\hline Secondary & 2.8 & 3.6 & 5.9 & 9.3 & 9.3 & 12.9 \\
\hline Higher secondary & 0.9 & 1.4 & 2.6 & 4.2 & 4.6 & 6.6 \\
\hline Diploma/certificate & -- & 0.5 & 0.5 & -- & 1.0 & 1.1 \\
\hline Graduate above & 0.6 & 0.9 & 2.1 & 3.3 & 3.8 & 5.0 \\
\hline \multirow[t]{2}{*}{ All } & 100.0 & 100.0 & 100.0 & 100.0 & 100.0 & 100.0 \\
\hline & & & \multicolumn{2}{|c|}{ Urban } & & \\
\hline Not literate & 43.9 & 37.3 & 27.9 & 16.0 & 13.1 & 11.2 \\
\hline $\begin{array}{l}\text { Literate\&up to } \\
\text { primary }\end{array}$ & 17.6 & 20.3 & 19.5 & 21.9 & 22.7 & 18.8 \\
\hline Middle & 10.3 & 11.9 & 12.3 & 18.8 & 19.4 & 17.5 \\
\hline Secondary & 8.8 & 7.3 & 9.1 & 16.9 & 15.0 & 16.5 \\
\hline Higher secondary & 5.5 & 5.1 & 7.1 & 9.4 & 9.2 & 10.9 \\
\hline Diploma/certificate & -- & 3.4 & 2.3 & -- & 3.7 & 2.9 \\
\hline Graduate above & 13.9 & 14.7 & 21.8 & 16.8 & 16.9 & 22.2 \\
\hline All & 100.0 & 100.0 & 100.0 & 100.0 & 100.0 & 100.0 \\
\hline Source: NSSO (2014) & & & & & & \\
\hline
\end{tabular}

Regarding skill development, only 10 percent of the workforce in the age group of 15-59 years received some form of vocational training in 2009-10. The percentage of workers who received vocational training was the highest in the service sector with 33 percent. This is followed by manufacturing ( 31 percent), agriculture (27 percent). In the non-manufacturing and allied activities, only 9 percent had vocational training (GOI, 2013). But, the main problem is that vast majority of workers have non-formal vocational training. Only 11 million workers had formal training while 33 million workers had non-formal training. The present government has also emphasized the importance of skill development. This has to be given priority to take advantage of demographic dividend (Radhakrishna, 2015).

(d) Slow social sector development.

Although there have been achievements in social sector during the reform period, the progress has been very slow. India has succeeded in growth but there is a failure in progress of social indicators. The country is not only behind China but the progress is slower than many of the Asian countries. It is known that India's rank of human development index (HDI) is lower compared to many other developing countries. Basically, the argument is that compared to economic growth, reduction in inequality, hunger, and malnutrition is much slower. Improvement in health and quality of education is slower. There is a disconnect between economic growth and malnutrition. Slow reduction in malnutrition is one of the failures in the post-reform period. We know that the solutions lie in improving agriculture, health, women empowerment and nutrition programs. Also, regional disparities are high in human development. Southern states have done better than Northern and Eastern states. There are five problems in the social sector: (a) low levels of social indicators (b) slow progress (c) significant regional, social and gender disparities (d) low level and slow growth in public expenditures particularly on health and (e) poor quality delivery systems. The social sector should be one of the focus areas for sustainability of economic growth and equity (Rangarajan, 2015 C).

\section{(e) Governance Failures}

Last and fifth one is governance. Reforms were expected to improve governance at various levels. However, there are new problems in governance and persistence of old problems including corruption. Apart from many achievements, the post-reform period also witnessed many scams in the financial and real sectors. These scams in the last 25 years could have been avoided with better governance. There has been a nexus between politicians, business people, and bureaucracy. Crony capitalism is one of the factors for corruption. Jalan (2006) says the interface between politics, economics and governance, and their combined effect on the functioning of our democracy, which will largely determine India's future (Jalan, 2006). A study on the 
performance of Karnataka's Lokayukta suggests that without an overhaul of the country's administrative structure, ex-post prosecution of corruption or withdrawal from economic activities can not reduce corruption (Babu et al, 2013) at present the design of anti-corruption ombudsman leaves a lot to the personality of Lokayukta. The analysis also suggests that the overburdened legal system needs legal reforms. Many people feel that governance problem is the biggest constraint for achieving our development goals in the country (Baviskar, 2015).

\section{(f) Poverty across Social Groups}

Another way of looking at inequality is to examine the poverty ratios across social groups. Poverty declined much faster for all the social groups during the period 2004-05 to 2011-12 as compared to the period1993-94 to 2004-05 (Table 9). The rate of decline in poverty is the highest for SCs. The decline in poverty for SCs and OBCs exceeded the national average during the period 2004-05 to 2011-12. Poverty decline for STs was more or less similar to that of the national average. It looks like SCs, STs, and OBCs benefited equally or more in the high growth phase of 2004-05 to 2011-12. However, the poverty levels are higher for STs and SCs as compared to other groups. Particularly the poverty ratio of STs was two times to that of the national average in 2011-12. There is a need to focus on policies relating to STs for the reduction in their poverty (Sharma, 2013).

Table 3. Poverty by Social Groups, 1993-94 to 2011-12

\begin{tabular}{|c|c|c|c|c|c|c|}
\hline \multirow{3}{*}{$\begin{array}{l}\text { Social } \\
\text { Groups }\end{array}$} & \multirow{2}{*}{$\begin{array}{l}\text { Share in } \\
\text { Population }\end{array}$} & \multirow{2}{*}{\multicolumn{3}{|c|}{$\frac{\text { Per cent Population Below Tendulkar }}{\text { Committee Poverty Line }}$}} & \multirow{2}{*}{\multicolumn{2}{|c|}{\begin{tabular}{l|l} 
Percentage & Point \\
Poverty Reduction
\end{tabular}}} \\
\hline & & & & & & \\
\hline & $2011-12$ & $1993-94$ & 2004-05 & $2011-12$ & $\begin{array}{l}1993-94 \text { to } \\
2004-05\end{array}$ & $\begin{array}{l}2004-05 \text { to } \\
2011-12\end{array}$ \\
\hline & \multicolumn{6}{|c|}{ Rural } \\
\hline ST & 11.1 & 65.9 & 62.3 & 45.3 & 3.7 & 16.9 \\
\hline $\mathrm{SC}$ & 20.8 & 62.4 & 53.5 & 31.5 & 8.9 & 22.0 \\
\hline OBC & 45.0 & 44.0 & 39.8 & 22.7 & 9.0 & 17.1 \\
\hline $\mathrm{FC}$ & 23.0 & & 27.1 & 15.5 & 7.2 & 11.6 \\
\hline \multirow[t]{2}{*}{ All } & 100.0 & 50.3 & 41.8 & 25.4 & 8.5 & 16.4 \\
\hline & \multicolumn{6}{|c|}{ Urban } \\
\hline ST & 3.5 & 41.1 & 35.5 & 24.1 & 5.6 & 11.4 \\
\hline $\mathrm{SC}$ & 14.6 & 51.7 & 40.6 & 21.7 & 11.1 & 18.8 \\
\hline $\mathrm{OBC}$ & 41.6 & 28.2 & 30.6 & 15.4 & 5.8 & 15.2 \\
\hline $\mathrm{FC}$ & 40.3 & & 16.1 & 8.1 & & 8.0 \\
\hline \multirow[t]{2}{*}{ All } & 100.0 & 31.9 & 25.7 & 13.7 & 6.2 & 12.0 \\
\hline & \multicolumn{6}{|c|}{ Rural+Urban } \\
\hline ST & 8.9 & 63.7 & 60.0 & 43.0 & 3.7 & 17.0 \\
\hline $\mathrm{SC}$ & 19.0 & 60.5 & 50.9 & 29.4 & 9.6 & 21.5 \\
\hline OBC & 44.1 & 39.5 & 37.8 & 20.7 & 8.1 & 17.1 \\
\hline $\mathrm{FC}$ & 28.0 & & 23.0 & 12.5 & 7.2 & 10.5 \\
\hline All & 100.0 & 45.7 & 37.7 & 22.0 & 8.0 & 15.7 \\
\hline
\end{tabular}

Source: Panagariya and More (2013)

(g) Inequality and Human Development

Higher inequality can lead to lower human development. A study by Suryanarana (2013) estimates both Human Development Index (HDI) and inequality adjusted HDI for all India and States (Table 10).

Table :4 Human Development Index (HDI) and Inequality Adjusted Human Development Index (IHDI)

\begin{tabular}{|l|l|l|l|l|l|}
\hline States & HDI & IHDI & $\begin{array}{l}\text { Loss } \\
(\%)\end{array}$ & Rank HDI & Rank IHDI \\
\hline & & & & & \\
\hline A.P. & 0.485 & 0.332 & 31.6 & 19 & 20 \\
\hline Bihar & 0.447 & 0.303 & 32.1 & 26 & 24 \\
\hline & & & & & \\
\hline Chattisgarh & 0.458 & 0.297 & 35.1 & 24 & 25 \\
\hline & & & & & \\
\hline
\end{tabular}


Does India Increasing Potential Inclusive Growth Polices? A Critical Analysis

\begin{tabular}{|c|c|c|c|c|c|}
\hline Gujarat & 0.514 & 0.363 & 29.5 & 15 & 13 \\
\hline Jharkhand & 0.470 & 0.312 & 33.7 & 21 & 21 \\
\hline Karnataka & 0.508 & 0.353 & 30.5 & 18 & 18 \\
\hline Kerala & 0.625 & 0.520 & 16.8 & 1 & 1 \\
\hline M.P. & 0.451 & 0.290 & 35.7 & 25 & 27 \\
\hline Maharashtra & 0.549 & 0.397 & 27.8 & 7 & 8 \\
\hline Odisha & 0.442 & 0.296 & 33.1 & 27 & 26 \\
\hline Punjab & 0.569 & 0.410 & 28.0 & 4 & 4 \\
\hline Rajasthan & 0.468 & 0.308 & 34.0 & 23 & 22 \\
\hline Tamil Nadu & 0.544 & 0.396 & 27.3 & 9 & 9 \\
\hline U.P. & 0.468 & 0.307 & 34.5 & 22 & 23 \\
\hline West Beng. & 0.509 & 0.360 & 29.3 & 17 & 14 \\
\hline All India & 0.504 & 0.343 & 32.0 & -- & -- \\
\hline
\end{tabular}

The rank of Madhya Pradesh for inequality adjusted HDI is the lowest while Kerala has the highest rank. The average loss in HDI due to inequality at the All-India level is $32 \%$. It is the highest for Madhya Pradesh (36\%) and Chhattisgarh (35\%) and the lowest for Kerala (17\%). The loss due to inequality is the highest with respect to education dimension (43\%), followed by health (34\%) and income (16\%). It shows that inequalities in non-income indicators like education and health are higher than that of income. The analysis also shows that with lower inequalities, HDI would have been much higher(Suryanarayana, 2013)

\section{(h) Inequality and Growth}

Generally, equity and growth are complements rather than trade-offs. The increase in inequality can reduce the impact of growth on poverty. Higher inequality may adversely affect growth in a number of ways such as social discontent, reduction in the size of domestic market due to lower demand etc. Thus growth with increasing inequalities may not be sustainable. Living with high inequalities may lead to lower than expected growth and all the negative consequences of inequalities.

\section{METHODOLOGY}

This section discusses the measurement of Indian inclusive growth policies. Inclusive growth may be measured using the idea of a social opportunity function, which is similar to a social welfare function. Hence, it can be said that inclusive growth leads to the maximization of the social opportunity function. To be consistent with our definition of inclusive growth, the researcher proposes a methodology to measure growth inclusiveness in terms of increasing the social opportunity function, which depends on two factors: (i) average opportunities available to the population, and (ii) how opportunities are shared or distributed among the population. This social opportunity function gives greater weight to the opportunities enjoyed by the poor: the poorer a person is, the greater the weight will be. Such a weighting scheme will ensure that opportunities created for the poor are more important than those created for the non-poor, i.e., if the opportunity enjoyed by a person is transferred to a poorer person in society, then social opportunity must increase, thus making growth more inclusive. Suppose there are $\mathrm{n}$ persons in the population with incomes $X_{1}, X_{2} \ldots \ldots X_{n}$ where $X_{1}$ is the poorest person and $X_{n}$ is the richest hen we define a social welfare function as

$w=w\left(X_{1}, X_{2}, \ldots \ldots \ldots, X_{n}\right)(1)$

which is an increasing function of its arguments. Similar to this idea of social welfare function, we can define a social opportunity function: 


$$
0=0\left(Y_{1}, Y_{2}, \ldots \ldots \ldots \ldots, Y_{n}\right)(2)
$$

where $y_{i}$ is the opportunity enjoyed by the $i$ th person who has income $X_{i}$ Opportunity can be defined in terms of various services, e.g., access to a health or educational service, access to job opportunity in the labor market, etc.

$y_{i}$ can take binary values 0 and 100. It takes the value 0 if the $i$ th person is deprived of a certain opportunity and takes the value 100 when the $i$ th person has that opportunity. The average opportunity for the population is then defined as

$$
\bar{Y}=\frac{1}{n} \sum_{i-1}^{n} y_{i}
$$

Which is the percentage of the population who enjoys a given opportunity?

The opportunity function should be an increasing function of its arguments. If the opportunity of any person increases, then social opportunity function must increase. Economic growth must expand the average opportunities available to the population. This is a necessary, but, by no means, sufficient requirement to achieve inclusive growth. The poor are generally constrained in availing these opportunities. Inclusive growth therefore should not only expand average opportunities, but also improve the distribution of opportunities across the population. If our development model is entirely focused on the maximization of $\bar{Y}$ as defined in (3), we are completely ignoring the distribution of opportunities. To bring in distribution considerations, researcher requires the social opportunity function to satisfy the transfer principle: any transfer of opportunity from a poorer person to a richer person must decrease the social opportunity function. Without loss of generality, researcher can suppose that tamount of opportunity is transferred from a poorer person with income $X_{1}$ to a richer person with income $X_{2}$. After the transfer, the poorer person will have $Y_{1},-$ topportunities and the richer person will enjoy $Y_{2}$ + topportunities. Such transfers should reduce the social opportunity function. Following from that, the social opportunity function must satisfy the following requirement

$0\left(y_{1}-t, y_{2}+t, y_{3}, \ldots \ldots, y_{n}\right) \leq 0\left(y_{1}, y_{2}, y_{3}, \ldots \ldots, y_{n}\right)$

which must hold for all non-negative values of $t$ ?

Let us denote the opportunity distribution vector $Q(t)$ by

$Q(t) \approx\left(y_{1}-t, y_{2}+t, y_{3}, \ldots \ldots \ldots, y_{n}\right)$

From (4), it can be said that the vector $Q(0)$ is opportunity superior to the vector $Q(t)$, i.e.,the vector $Q(0)$ will always provide equal or greater social opportunities than the vector $Q(t)$ for all non-negative values of $t$. A cumulative distribution of $Q(t)$ can be constructed as:

$Q^{c}(t) \approx\left(y_{1}-t, \frac{y_{1}+y_{2}}{2}, \frac{y_{1}+y_{2}+y_{3}}{3}, \ldots \ldots \ldots \ldots . \frac{y_{1}+y_{2} \ldots \ldots+y_{n}}{n}\right)(6)$

which is the distribution of cumulative means of $Q(t)$ when the individuals are arranged in ascending order of their incomes. $Q^{c}(t)$ represents the concentration curve of the distribution $Q(t)$. Similarly, the concentration curve of the distribution $Q(0)$ is given by

$$
Q^{c}(0) \approx\left(y_{1} \frac{y_{1}+y_{2}}{2}, \frac{y_{1}+y_{2}+y_{3}}{3}, \ldots \ldots ., \frac{y_{1}+y_{2} \ldots .+y_{n}}{n}\right)(7)
$$

Comparing (6) and (7) it is evident that the concentration curve $Q \mathrm{c}(0)$ will always be higher than the concentration curve $Q^{c}(t)$ for all $t$ and $t>0$ (i.e., non-negative values of $t$ ). Thus researcher have shown that if the distribution $y$ denotes opportunity superior to the distribution $y^{*}$, then the distribution $y$ will always have a higher concentration curve. Similarly, researcher can prove that if the distribution $y$ has a higher concentration curve than $y^{*}$, then distribution $y$ will always give a greater social opportunity function. Thus, by looking at the concentration curves of two distributions, researcher can judge which of these two will provide greater social opportunities, provided the two concentration curves do not intersect.

To make the above idea operational, it will be useful to formulate the problem in terms of continuous distribution. Suppose we arrange the population in ascending order of their incomes. Suppose further that $\bar{y}_{p}$ is 
the average opportunity enjoyed by the bottom pper cent of the population, where $p$ varies from 0 to 100 and $\bar{y}$ is the mean opportunity that is available to the whole population, then $\bar{y}_{p}$ will be equal to $\bar{y}$ when $p=100$ (which covers the whole population).

As $\bar{y}_{p}$ varies with $p$, we can draw a curve $\bar{y}_{p}$ for different values of $p$. This is, in fact, aconcentration curve of opportunity when the individuals are arranged in ascending order of their incomes. Researcher may call this curve as the opportunity curve: the higher the curve, the greater the social opportunity function. Thus growth will be inclusive if it shifts the opportunity curve upward at all points. If the entire opportunity curve shifts upward, this implies that everyone in society including the poor is enjoying an increase in opportunities, and hence we may call such a growth process as unambiguously inclusive. The degree of inclusiveness, however, will depend on (i) how much the curve is shifting upward and (ii) in which part of the income distribution the shift is taking place.

If the opportunity curve is sloping downward, then we can say that opportunities available to the poor are more than those available to the non-poor (i.e., the opportunities are distributed equitably). Similarly, if the curve is sloping upward, opportunities are distributed inequitably (anti-poor). Figure 3 depicts two opportunity curves with the same mean $(\bar{y})$ : one is sloping upward $(\mathrm{AB})$ and the other is sloping downward $(\mathrm{CB})$. The curve $\mathrm{CB}$ indicates equitable distribution of opportunities, meaning that the poor at the bottom end of the distribution have greater opportunity than the non-poor at the top end. The upward-sloping curve $A B$, on the other hand, indicates the opposite: the poor enjoy fewer opportunities than the non-poor.

Figure: 3 Access to an opportunity

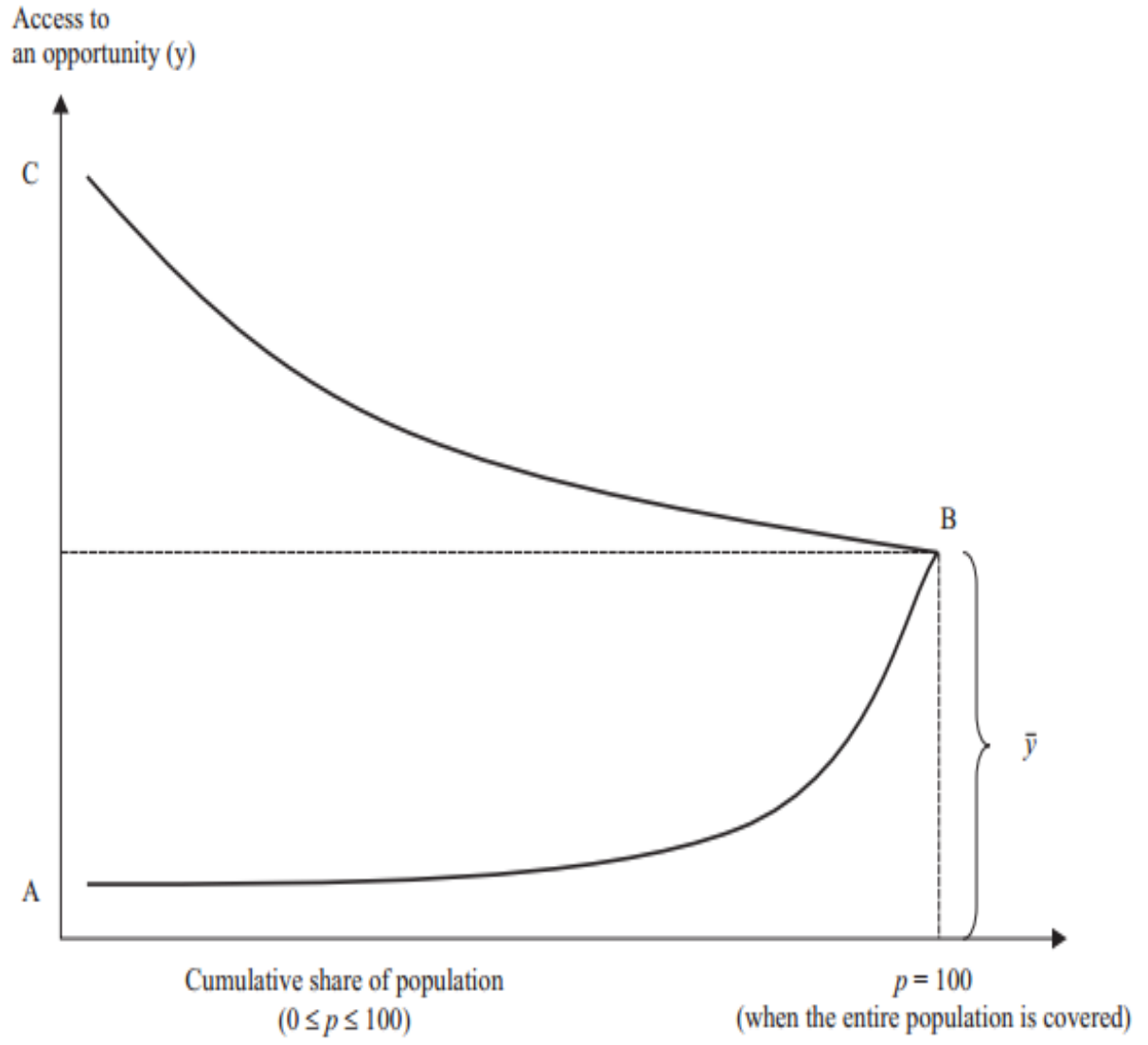

Sources: Researcher design

The opportunity curve can be useful to assess the pattern of growth that is defined in termsof access to and equity of opportunities available to the population, without specifying a social opportunity function. However, it is unable to quantify the precise magnitude of the change, i.e., one cannot be conclusive as to how much changes in opportunities have occurred over time. In this respect, the opportunity curve provides only partial rankings of opportunity distributions.

To be able to capture the magnitude of the change in opportunity distributions, we need tomake a stronger assumption about the form of the social opportunity function used. One simple form of the social opportunity function may be obtained by calculating an index from the area under the opportunity curve as denoted below: 


$$
\bar{y}^{*}=\int_{0}^{1} \bar{y}_{p} d p(8)
$$

which is our proposed Opportunity Index (OI). The greater $\bar{y}^{*}$ is, the greater will be the opportunities available to the population. Our development objective should be to maximize the value of $\bar{y}^{*}$

If everyone in the population enjoys exactly the same opportunity, then it can be shown that $\bar{y}^{*}$ will be equal to $\bar{y}$. As such, the deviation of $\bar{y}^{*}$ from $\bar{y}$ provides an indication of how opportunities are distributed across the population. If $\bar{y}^{*}$ is greater than $\bar{y}$, then opportunities are equitably distributed (pro-poor). Similarly, if $\bar{y}^{*}$ is less than $\bar{y}$, then opportunities are inequitably distributed (antipoor). Thus we propose an Equity Index of Opportunity (EIO):

$$
\emptyset=\frac{\bar{y}^{*}}{\bar{y}}
$$

which implies that opportunities are equitably (inequitably) distributed if $\phi$ is greater (less) than 1. From (9), it immediately follows that

$$
\bar{y}^{*}=\varnothing \bar{y}
$$

which shows that our proposed OI is the product of EIO and the average level of opportunities available to the population. To achieve inclusive growth, we need to increase $\bar{y}^{*}$ which can be accomplished by:

(i) increasing the average level of opportunities $\bar{y}$, (ii) increasing the equity index of opportunities $\phi$, or (iii) both (i) and (ii). To understand the dynamics of inclusive growth, we differentiate (10) both sides to obtain:

$$
d \bar{y}^{*}=\varphi d \bar{y}+\bar{y} d \varphi(11)
$$

where $d \bar{y}^{*}$ measures the change in the degree of growth inclusiveness. Growth becomes more inclusive if $d \bar{y}^{*}>$ 0 . The first term in the right side of equation (11) is the contribution to inclusiveness of growth by increasing the average opportunity in society when the relative distribution of the opportunity does not change; the second term of the equation shows the contribution of changes in the distribution when the average opportunity does not change.The two contributions carry important policy implications: they tell us how government policies or development strategies can influence the inclusiveness of growth. Consider a case where the second term of the right side in equation (11) is larger than the first term. In this case, a developmentstrategy is focused on creating opportunities for the poor, rather than on expanding the average opportunities for all. There could be a trade-off between $\bar{y}$ and $\phi$, which will be evident from the first and second terms of the equation: if $\bar{y}$ is increased, $\phi$ may decrease and vice versa. If the first term is positive but the second term is negative, higher average opportunity for the society as a whole is achieved at the expense of reducing equitable access to opportunity. Similarly, if the first term is negative but the second term is positive, then the equity objective is achieved at the cost of the foregone average opportunity for the society. The inclusiveness of growth will depend on which contribution outweighs the other. It should be noted that there will not always be a trade-off between $\bar{y}$ and $\phi$ : one can increase (or decease) concurrently with the other. If both terms are positive $(\mathrm{d} \bar{y}>0$ and $\mathrm{d} \varphi>0)$, growth will always be inclusive; similarly, if both terms are negative $(\mathrm{d} \bar{y}>0$ and $\mathrm{d} \varphi>0$ ), growth not will always be inclusive.

In addition, it will be interesting to investigate if one unit of increase in the average opportunity $\bar{y}$ will result in more than one unit of increase in the degree of growth inclusiveness, when the initial value of $\phi$ is greater than 1 (i.e., opportunity is equitably distributed in favour of the poor). Thus, the initial distribution of opportunity plays an important role in determining inclusive growth: the more equitable the initial distribution, the greater the impact will be on the growth inclusiveness by expanding the average opportunity for all. Similarly, the initial level of $\bar{y}$ can also enhance the impact of equity on growth inclusiveness. These findings, therefore, suggest that both $\bar{y}$ and $\phi$ are important policy instruments that reinforce each other in achieving a more inclusive growth.

\section{Empirical Analysis}

The proposed methodology outlined has used the National Sample Survey (NSS) conducted a nationwide survey on different accepts. This survey conducted as household survey is micro unit recorded. In terms of the social opportunity function, inclusive growth can be measured by two approaches, namely partial and full. The partial approach is derived based on a curve called the "opportunity curve." The full approach is based on an index quantified from the area under the opportunity curve. The opportunity curve slopes downward, and then it suggests that opportunities are distributed equitably among the population. Conversely, an upward sloping curve suggests inequitable distribution of opportunities among the people. The slope of the opportunity curve will be helpful in examining the extent to which opportunities are distributed equally or unequally among the people at a given point in time. 
Figure: 4 Opportunity Curve for Employment Opportunity in India

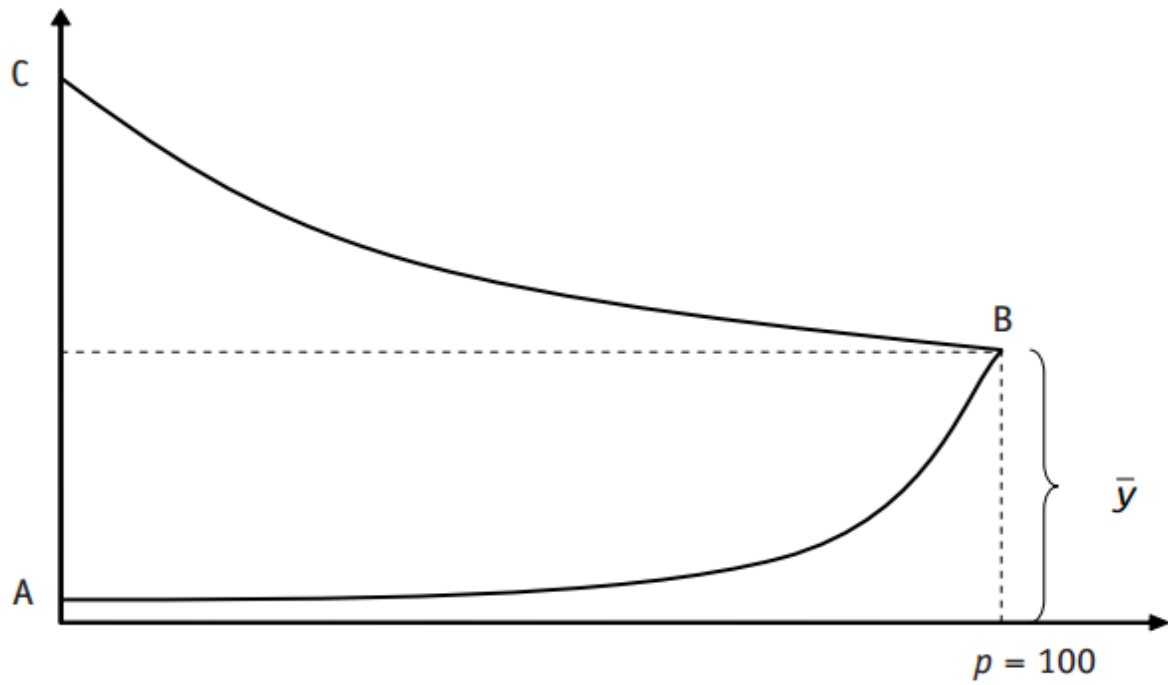

(when the entire population is covered)

Source: Authors' calculations based on the 2007 and 2017 APIS.

The figure indicates that the opportunity curve for employment opportunities available to the population in India. Indian accepts exploring that the opportunities curve; there are two points to be considered. First, when the entire population is covered $(\mathrm{p}=100)$, the opportunity curve overlaps with the average job opportunity available for the population. Hence, the average per capita job opportunity in the Indian economy was 0.407 in 2016, or almost $41 \%$ per cent of the population was employed in the economy. Second, the opportunity curve is upward-sloping. This suggests that the poor belonging to the bottom of the income distribution have less job opportunities than the non-poor.

The results indicate that while more than half of the male population is employed, the corresponding figure for the female population is only 30 per cent. This indicates greater access to job opportunities by the male population. Moreover, the distribution of job opportunities across the male population is shown to be more equitable than that of the female population. This finding is also supported by the opportunity curves for the two groups (see Figures 4 and 5). The entire curve for job opportunity among males (shown in Figure 5) lies above the opportunity curve for females (shown in Figure 5). At every income level, males tend to have more job opportunities than their female counterparts. This implies that (i) men enjoy greater job opportunities on average and (ii) the distribution of job opportunities among men is more equitable than among women.

Figure: 5 Opportunity curve for employment opportunities among the male population in India

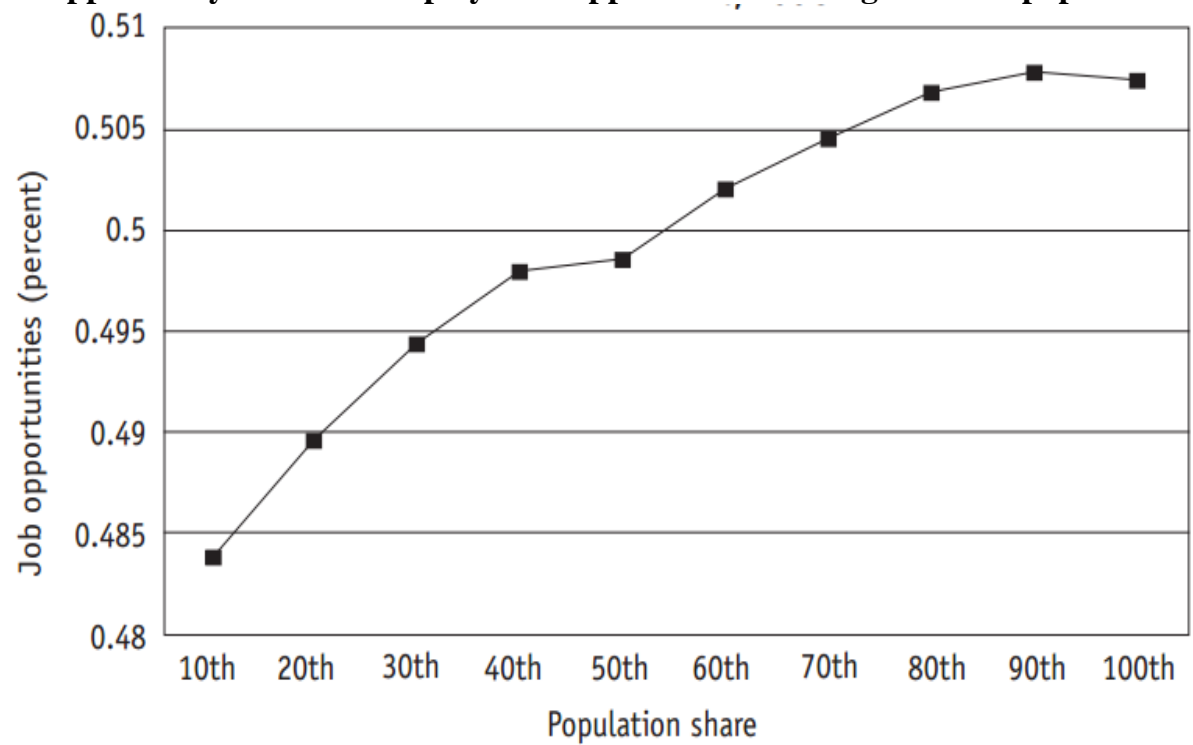

Source: Authors' calculations based on the 1998 and 2004 APIS. 
Figure: 6 Opportunity curve for employment opportunities among the female population in India

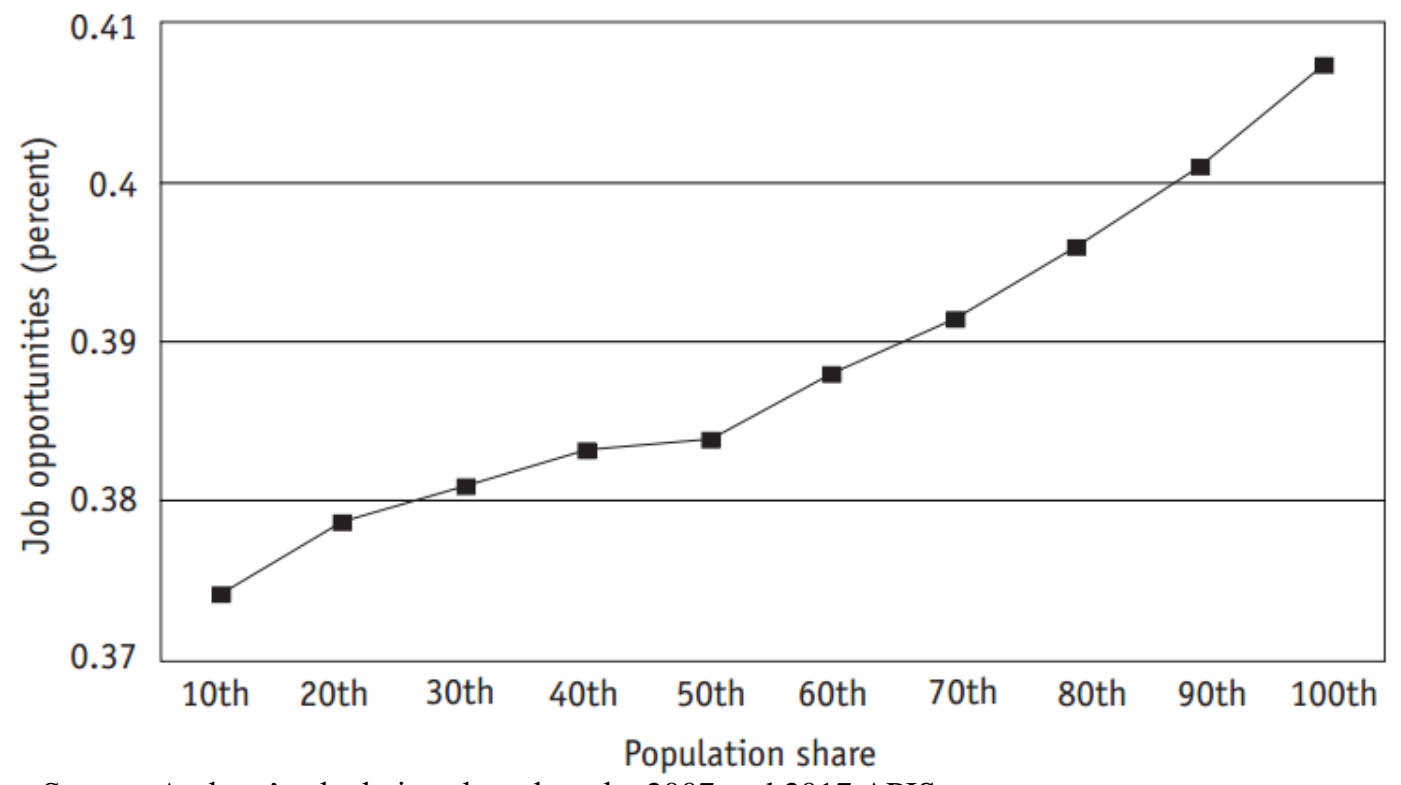

Source: Authors' calculations based on the 2007 and 2017 APIS.

The opportunity curve can be a useful tool in understanding the pattern of inclusive growth in terms of opportunities available to the population. But it does not provide a complete ranking of opportunity distributions (e.g., when the two curves cross each other). Moreover, this curve does not capture the magnitude of inclusive growth in terms of opportunities. To compensate for these shortfalls, the opportunity index is estimated, calculated from the area under the opportunity curve. The greater the value of OI, the greater will be the opportunities available to the population including the poor. The proposed OI is simply the product of the average level of opportunities available to the population and the equity index of opportunity. Note that the EIO captures the extent to which opportunities are distributed equally (or unequally) among the people. Hence, if the EIO takes a value greater (less) than 1, one can say that opportunities are distributed equitably (inequitably). Equivalently, one can define growth as inclusive (not inclusive) if the estimated value of OI is greater (less) than the average opportunities available to all.

To effectively achieve inclusive growth, the objective should be to increase the value of the Opportunity Index. Maximizing the value of OI can be achieved by: (i) increasing the average level of opportunities available to all; (ii) increasing the equity index of opportunity through an equitable distribution of opportunities; or (iii) both (i) and (ii). This methodology is applied in the case of India. The results in Tables 57 show (i) whether basic opportunities in health, education, and infrastructure are provided to all; and (ii) whether those opportunities are equally shared among the population. Table 5 is concerned with opportunities in terms of access to health facilities, utilized when individuals are sick. The results suggest that in 2017, only $18.92 \%$ of sick individuals sought treatment. Moreover, the overall health services in Indian appear to be inequitable in the sense that the health services are largely utilized by the top end of the income distribution. This is depicted in the opportunity curve in Figure 6. The inequitable opportunity of health services is also reflected by the value of the EIO for the overall health service (0.90) is less than 1, or the value of OI (17.08) being less than the average opportunity for the population (18.92). Table 5 also shows the types of health facilities utilized by sick individuals in India. Nationally, majority of the people prefer private clinics or rural health Centres (RHC) health centres: $5.13 \%$ of sick people utilize private clinics and another $4.79 \%$ utilize RHC health centres.

Table:5 Opportunity Index for Access to Various Health Facilities in India,

\begin{tabular}{|c|c|c|}
\hline Population Share & 2007 & 2017 \\
\hline 10 & 37.38 & 30.8 \\
\hline 20 & 37.14 & 33.39 \\
\hline 30 & 38.19 & 35.07 \\
\hline 40 & 39.37 & 36.81 \\
\hline 50 & 40.4 & 38.86 \\
\hline
\end{tabular}




\begin{tabular}{|c|c|c|}
\hline 60 & 41.38 & 38.86 \\
\hline 70 & 42.27 & 39.89 \\
\hline 80 & 43.23 & 41.27 \\
\hline 90 & 44.15 & 42.62 \\
\hline 100 & 45.93 & 44.31 \\
\hline Opportunity Index & 40.93 & 38.11 \\
\hline $\begin{array}{l}\text { Equity Index of } \\
\text { Opportunity }\end{array}$ & 0.93 & 0.86 \\
\hline Comments & $\begin{array}{l}\text { Not } \\
\text { equitable }\end{array}$ & $\begin{array}{l}\text { Not } \\
\text { equitable }\end{array}$ \\
\hline
\end{tabular}

Source: Authors' calculations based on the 2007 and 2017 APIS

Figure: 7 Opportunity curve for health services in the India,

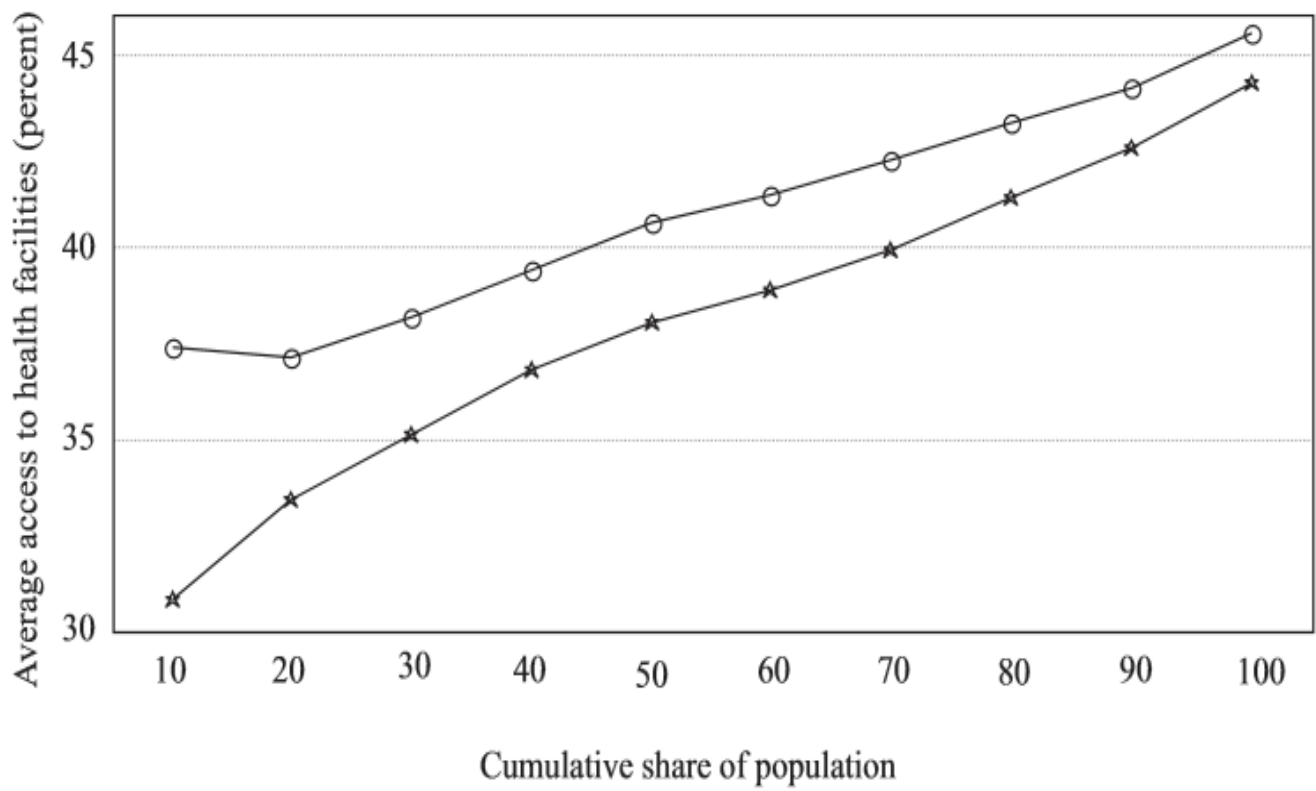

Source: Authors' calculations based on the 2007 and 2017 APIS.

More interestingly, although the average opportunity in terms of access to private clinics is greater than the others, the distribution is highly skewed toward the top end of the income distribution. In other words, the health service provided by private clinics tends to be highly inequitable in India, the EIO for the private clinic (0.64) is less than 1, or the OI (3.27) is less than the average opportunity for the population of 5.13. Similarly, the health services provided by the government and private hospitals are heavily utilized by the richer segments of the society. This is also evident in Figure 7. On the contrary, health facilities such as Rural Health Centres RHC and Urban health centers are utilized more by the people at the lower end of the income distribution. This is evident in the downward-sloping opportunity curves shown in Figure 8. The values for EIO and OI confirm the finding that both health services are highly utilized by the poor segments of the society The methodology is applied similarly to explore to what extent the opportunities of education at primary and secondary levels are shared among children from the poor and non-poor households in India. Table 6 shows that a very high proportion (95.9\%) of children aged between 5 and 12 years attend primary school in India. The corresponding figure for secondary education is rather lower at $83.25 \%$ of children aged between $12-16$ years. These school attendance figures do not indicate whether the educational opportunities are equally shared among the children irrespective of their income status. The distribution of the educational opportunities is, in fact, unequal: it is even more unequal at the secondary level. In this case, the opportunity curves for both educational levels have an upward slope. This suggests that children at the bottom end of the income distribution have lower access to primary and secondary education. This finding is confirmed by the estimated opportunity indices: the values of the EIO are lower than 1 and the values of the OI are lower than the national average at both primary and secondary levels. 
Table: 6 Opportunity Index for Access to Primary and Secondary Schools in India

\begin{tabular}{|c|c|c|c|c|}
\hline \multirow[t]{2}{*}{ Population Share } & \multicolumn{2}{|c|}{$\begin{array}{c}\text { Primary } \\
\text { Age 5-12 } \\
\text { Attending School }\end{array}$} & \multicolumn{2}{|c|}{$\begin{array}{c}\text { Secondary } \\
\text { Age 12-16 } \\
\text { Attending School }\end{array}$} \\
\hline & 2007 & 2017 & 2007 & 2017 \\
\hline $10^{\text {th }}$ & 89.39 & 89.88 & 53.44 & 53.93 \\
\hline $20^{\text {th }}$ & 90.45 & 91.49 & 57.29 & 57.74 \\
\hline $30^{\text {th }}$ & 91.78 & 92.71 & 59.57 & 60.78 \\
\hline $40^{\text {th }}$ & 92.76 & 93.57 & 61.73 & 62.94 \\
\hline $50^{\text {th }}$ & 93.31 & 94.24 & 65.59 & \\
\hline $60^{\text {th }}$ & 93.9 & 94.96 & 65.59 & 67.06 \\
\hline $70^{\text {th }}$ & 94.42 & 95.39 & 67.33 & 68.78 \\
\hline $80^{\text {th }}$ & 94.91 & 95.8 & 69.03 & 70.66 \\
\hline $90^{\text {th }}$ & 95.36 & 96.16 & 71.22 & 72.83 \\
\hline $100^{\text {th }}$ & 95.75 & 96.07 & 64.26 & 65.46 \\
\hline Opportunity index & 93.2 & 94.07 & 64.26 & 65.46 \\
\hline $\begin{array}{c}\text { Equity index of } \\
\text { opportunity }\end{array}$ & 0.97 & 0.97 & 0.87 & 0.87 \\
\hline Comments & Not equitable & Not equitable & Not equitable & Not equitable \\
\hline
\end{tabular}

Source: Authors' calculations based on the 2007 and 2017 APIS

Figure:8 Opportunity Index for Access to Primary and Secondary Schools in India

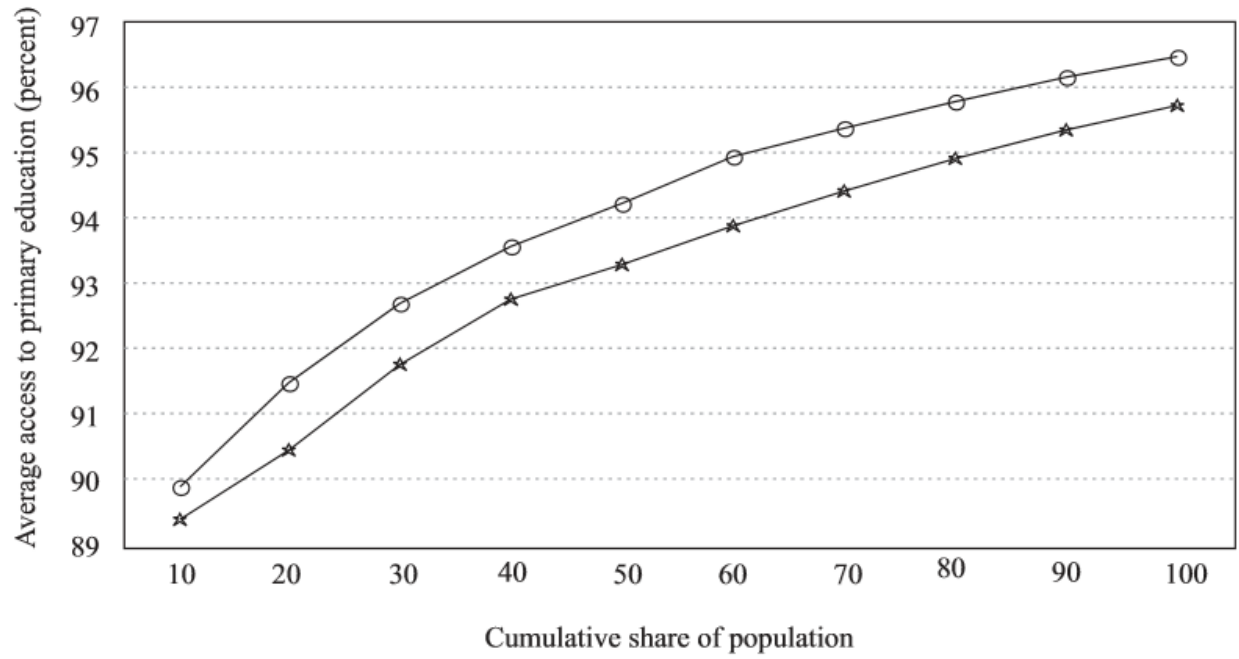

Source: Authors' calculations based on the 1998 and 2004 APIS.

Basic infrastructure services make significant contributions to people's well-being. Basic services such as electricity, sanitary toilets, and clean drinking water have direct impacts on people's health status and overall well-being. A number of studies reveal that a household's access to such basic services is highly and significantly correlated with a lower probability of being poor.

Table: 6 Opportunity Index for Access to Basic Infrastructure in India

\begin{tabular}{|c|c|c|c|}
\hline Percentile & Electricity & Sanitary Toilets & Clean Drinking Water \\
\hline 10 & 29.34 & 73.73 & 27.16 \\
\hline 20 & 35.67 & 76.18 & 29.01 \\
\hline 30 & 41.95 & 78.39 & 31.06 \\
\hline
\end{tabular}


Does India Increasing Potential Inclusive Growth Polices? A Critical Analysis

\begin{tabular}{|c|c|c|c|}
40 & 48.15 & 80.44 & 32.32 \\
\hline 50 & 53.42 & 82.26 & 33.73 \\
\hline 60 & 58.28 & 83.99 & 35.67 \\
\hline 70 & 62.62 & 85.54 & 37.71 \\
\hline 80 & 66.36 & 86.92 & 40.12 \\
\hline 90 & 69.58 & 88.37 & 45.48 \\
\hline 100 & 72.45 & 89.37 & 45.48 \\
\hline Opportunity index & 53.78 & 82.51 & 35.48 \\
\hline Equity index of opportunity & 0.74 & 0.92 & 0.78 \\
\hline Comments & Not equitable & Not equitable & Not equitable \\
\hline
\end{tabular}

In Table 6 shows that the benefits generated from all types of basic infrastructure services are not equally shared across the population, particularly for electricity and clean drinking water. The table shows that the poor at the lower end of the income distribution have far less access to basic infrastructure services than the rich at the upper end of the distribution

\section{DISCUSSIONS AND CONCLUSION}

The researcher was analyzed systematically to measure the inclusive growth. Here, the researcher given the importance of social welfare function and has attempted to introduce the idea of a social opportunity function. Growth is defined as inclusive if it increases the social opportunity function, which depends on two factors: (i) average opportunities available to the population and (ii) how opportunities are distributed in the population. This idea has been made operational by means of the opportunity curve, which has a one-to-one relationship with the social opportunity function: the higher the opportunity curve, the greater will be the social opportunity function. The opportunity curve can be empirically calculated using unit record household surveys. An empirical application to this paper shows that the opportunity curve is a useful device to analyze the inclusiveness of growth in quantitative terms.

But a more relevant question is how to assess the equitable opportunities over time. This type of dynamic analysis can be done by examining how the opportunity curves shift over periods. For instance, if the entire opportunity curve shifts upward, this suggests that growth is inclusive: growth is not only increasing the average opportunities available to the whole population but is also increasing the opportunities for the poor that belong to the bottom of the income distribution. The degree of inclusiveness will depend on (i) how much the curve shifts upward and (ii) in which part of the income distribution the shift takes place. This dynamic analysis will also allow for monitoring of the inclusiveness of growth over time for an individual country.

Finally, the proposed opportunity index is largely concerned with access to and equity of opportunities available to the population in society. In this respect, the proposed index is entirely different from indicators developed by the UNDP for the Millennium Development Goals (MDG) and the human development index (HDI). While our opportunity index describes the process to meet an end (or means to an end), the UNDP indicators focus on the outcomes of well-being (e.g., life expectancy at birth, gross enrolment rates, etc). Monitoring the means or process will ensure achieving the outcomes. Yet, the mere focus on achieving an outcome may ignore the means to meet the end. For instance, gross enrolment rate is an important indicator for both MDG and HDI. However, both MDG and HDI tend to simply focus on improvement in the average gross enrolment rate for a country. Assessing access to basic education is indeed important, but evaluating whether the access to basic education is equally shared among all segments of the population is also important (or may be more important than the issue of accessibility). The proposed opportunity index takes into account both issues.

Similar to the HDI, researcher may be able to develop a single composite index that consists of four key opportunities that are critical for people's overall well-being, namely employment, health and educational services, and material standard of living. This composite index may be useful for cross-states rankings, although it does suffer from two shortcomings: (i) it is derived based solely on the equity of opportunity among the population (i.e., average of the equity index of opportunity for five key opportunities); and (ii) the composite index may have the virtue of being simple but it uses a simple average of the five key components included in the index (i.e., equal weights assigned to each component). Developing an index that can fully address such shortcomings could be another scope for future research.

The research results indicate that gender gap is increasing. The opportunity curve can be a useful tool in understanding the pattern of inclusive growth in terms of opportunities available to the needy population. But it does not provide a complete ranking of opportunity distributions. Research results showed that this curve does 
not capture the magnitude of inclusive growth in terms of access to opportunities.Particularly basic infrastructure facilities are not reaching to needy poor people for example health services inequitable. This will help to many readers and policy makers to achieve inclusive growth better policies. The research results will have social implications (excluded people) for policy makers to formulate the better social inclusive growth policies.

\section{REFERNCE}

[1] Ahluwalia, M. (2007). Indian Inclusive Growth Strategies. New Delhi: Planning Commission.

[2] Ahluwalia, M. (2012). Prospects and Policy Challenges in the Twelfth Plan. Economic and Political weekly, Vol.46(No.21).

[3] Ali, I. a. (2007). Inclusive Growth toward a Prosperous Asia: Policy Implications. Manila: ERD Working Paper Asian Development Bank.

[4] Ali. J. (2007). Pro-poor to inclusive gowth: Asian Prescriptions. Manila: ERD Policy Brief No.48, Economics and Research Department, Asian Development Bank,

[5] Baviskar, A. (2015). Regional Dimensions of Social Movement in India, "Indian Rural Development Report 2013-14", IDFC. New Delhi: Oxford University Press.

[6] DW Report. (2016, 1 22). What is driving inequality in India? Retrieved May 10, 2016, from DW: http://www.dw.com/en/what-is-driving-inequality-in-india/a-18998489

[7] IMF. (2016, May 4). The Global Economy in 2016. Retrieved May 10, 2016, from Internaitonal Monetary Fund: http://www.imf.org/external/pubs/ft/survey/so/2016/INT010416A.htm

[8] Jalan, B. (2006). The Future of India: Politics, Economics and Governance. New Delhi: Penguin Books.

[9] Kakwani, N. a. (2000). "What is Pro-poor Growth?". Asian Development Review, vol. 18 (1), 1-16.

[10] Kannan, K. (2014). Interrogating Inclusive Growth: Poverty and Inequality in India. Economic and Political Weekly, 1-22.

[11] Kundu, U. R. (2016, March 18). What is behind high inequality in Kerala? Retrieved May 20, 2016, from Live Mint: http://www.livemint.com/Opinion/v9bWm59FOXpedpKb7GhqCO/What-is-behind-highinequality-in-Kerala.html

[12] Panagariya, A. a. (2013). Poverty by Social, Religious \& Economic Groups in India and its Large States: 1993-94 to 2011-12". USA: Columbia University, Program on Indian Economic Policie.

[13] Pyaralal Raghavan . (2016, March 7). Rising inequality in India and China can impact on pace and sustainability of growth in Asia. Retrieved May 10, 2016, from Time of India: http://blogs.timesofindia.indiatimes.com/minorityview/rising-inequality-in-india-and-china-can-impacton-pace-and-sustainability-of-growth-in-asia/

[14] Radhakrishna, R. (2015). Well-being, inequality, Poverty and Pathways out of poverty in India. Economic and Political Weekly, Vol.50, (No.41).

[15] Ramaswamy, K. a. (2013). Services-led Growth, Employment, Skill, and Job quality: A Study of Manufacturing and Service Sectors in Urban India. New Delhi: Oxford University Press.

[16] Rangarajan, C. a. (2015 C). How Deep is India's Poverty. Mumbia: Indian Express.

[17] Richard Samans, Jennifer Blanke, Gemma Corrigan, Margareta Drzeniek. (2015). The Inclusive Growth and Development Report 2015. Geneva: World Economic Forum.

[18] S, D. M. (2016). Economic Reforms, Poverty and Inequality. Mumbai: Indira Gandhi Institute of Development Research.

[19] Sharma, A. D. (2013). Disadvantage and discrimination in self-employment: Caste gaps in earnings in. United Institute of World, Development Economic Research. New Yorkd: United Nations University World Instutite of Development Economic Research.

[20] Singh, D. A. (2012). Inclusive Urban Development in India. Lucknow: Regional Centre for Urban and Environmental Studies.

[21] Suryanarayana, M. (2013). Promoting Human Development In India, in Dev S.Mahendra (ed., 2013), India Development Report, 2012-13. New Delhi: Oxford University Press. 